\title{
Effect of Genotype X Environment Interaction on the Performance of Hybrid Sorghum Genotypes in Moisture Stressed Areas of Ethiopia
}

\author{
Temesgen Teressa* Amare Seyoum Tamirat Bejiga Amare Nega Alemu Tirfessa \\ Ethiopian Institute of Agricultural Research, Melkassa Agricultural Research Center, P.O Box 436, Adama, \\ Ethiopia \\ Ethiopian Institute of Agricultural Research, P.O Box 2003, Addis Ababa, Ethiopia \\ Melkassa Agricultural Research Center, P.O Box 436, Adama, Ethiopia.
}

\begin{abstract}
Genotype $\mathrm{x}$ environment $(\mathrm{GxE})$ interaction and yield-stability analysis is an imperative in measuring varietal stability and suitability for cultivation over seasons and ecological zones. Developing high performing and stable genotypes across different locations is of most importance to plant breeders. This study was conducted using 84 hybrid lines to identify the most stable and high yielding genotypes. To gain these objective, multipleenvironmental trials (MET) was undertaken annually across locations. AMMI model has shown that the largest proportion of the total variation in grain yield was attributed to environments and somehow to genotypes. GGE bi-plot analysis also visualized the winner genotype at each area and to identify high yielding and stable genotypes. The genotype with the high yield in SR is G66, and in KB G27, G10, G79, in SH G25, G78, G86 and G68 while, in SR the best genotypes is G66. The other vertex genotypes (G1, G32, G51, 71 and G26 are poorest in all environments. Environments, AM and SH exerted strong interaction forces while the rest two did less. On the other hand, the genotypes near the origin are not sensitive to environmental interaction and those distant from the origins are sensitive and have large interaction. Hence, G1, G5, G66, G71, G18, G10 and G25 had more responsive since they were far away from the origin whereas the genotypes G54, G29, G23, G4, G9, G5, G43, G13 and G7 were close to the origin and hence they were less sensitive to environmental interactive forces while genotypes G38, G11, G45 and G76 were the most closest to the origin and hence had almost no interaction forces. Generally, G74 can be recommended for specific adaptation whereas G2 and G16 relatively for broader adaptation.
\end{abstract}

Keywords: AMMI; GEI; genotype; environment; model; stability, GGE biplot

DOI: $10.7176 / \mathrm{JNSR} / 13-5-04$

Publication date:March $31^{\text {st }} 2021$

\section{INTRODUCTION}

Sorghum [(Sorghum bicolor (L) Moench)] is a tropical plant belonging to the Poaceae family, and is one of the most important cereal crops in the world (Anglani, 1998). It is believed to be originated and domesticated in East Africa (4000-3000BC), most probably in Ethiopia-Sudan boarder (Doggett, 1988). Sorghum is a self-pollinated crop and has $2 \mathrm{n}=2 \mathrm{x}=20$ chromosomes, with small genome size of $\sim 750 \mathrm{MB}$ (Paterson, 1995) and is described as annual, with thick culms up to $5 \mathrm{~m}$ in height, often branched with many tillers.

Sorghum is the world's fifth most important staple food crop after wheat, rice, maize and barley and the fourth most important cereal crop in Africa next to maize, millet and rice (Mesfin, 2016). The world sorghum production is estimated to be 62.3 million tons per year from 42.1 million hectares of land and more than $70 \%$ of the cultivated lands are found in Africa and India (USDA, 2017). The average productivity of sorghum in Africa is around $1.62 \mathrm{t} / \mathrm{ha}$ and the total production area is 26.14 million hectares (USDA, 2017).

Ethiopia is the second largest sorghum producing country (5.16 million tons) in Eastern Africa next to Sudan (CSA, 2018). In Ethiopia, sorghum stands $3^{\text {rd }}$ in area and total production next to tef and maize and second next to maize in yield per hectare $(2.7 \mathrm{t} / \mathrm{ha})(\mathrm{CSA}, 2018)$. In the country cereals comprise $81.27 \%(10.21 \mathrm{million}$ ha) of the field crops of which, sorghum accounts for (14.97\%). Sorghum is grown in almost all regions occupying an estimated total land area of 1.9 million ha (CSA, 2018). The major sorghum producer regions of the country are Oromia (38.5\%), Amhara (32.9\%), Tigray (14.1\%), and Southern Nations and Nationalities People region (7.6\%) (CSA, 2018).

Sorghum is the major food and cash crop for the most food insecure farmers in the semi-arid areas which experience low and unreliable rainfall patterns, and which are not suitable for most other crops, including maize (Bibi et al., 2010). It is also used for animal feed and nowadays, sorghum has emerged as a smart crop for production of ethanol (biofuel). It supports about 500 million people serving as a source of food, feed, fiber and building material (Mesfin, 2016). In developed countries, sorghum is used primarily as animal feed and in the sugar, syrup, and molasses industry. In Ethiopia, sorghum provides more than one third of the cereal diet and is almost entirely grown by subsistence farmers to meet needs for food, income, feed and construction purposes (McGuire, 2007). Sorghum grain is mostly used for local markets and most of the sorghum produced in Ethiopia 
is consumed at household levels (Mesfin, 2016).

Unfortunately, in much of the sorghum growing areas of Africa including Ethiopia, bountiful crop harvests are curtailed by an array of production constraints including drought stress and severe infestation by the parasitic weed striga (Striga spp.). Drought stress caused by low and erratic rainfall and exasperates high temperature common in most sorghum growing regions and is the most important abiotic factor limiting sorghum productivity. Generally, about one-third of the world's arable land experiences water deficits, and in these areas crop yields are significantly reduced by drought (Boyer, 1982). Production of crop may be increased through improved efficiency in use of resources and through a well understanding and utilization of genotype by environment interaction (GEI). GEI is a main concern among breeders, geneticists, production agronomists, and farmers since its universal presence and consequences. Understanding and management of GEI has gone through several phases.

$\mathrm{GxE}$ interactions and effects of genetic background $\mathrm{GxE}$ interactions are complex phenomena which complicate the interpretation of genetical experiments. Because quantitative traits are influenced by the environment they often show varied degrees of GxE interactions. GxE interactions occur when two or more genotypes perform differently in different environments, and are thus described as differential genotypic sensitivities to environments (Yan and Tinker, 2006). Genotype $\mathrm{x}$ environment interaction is an important issue facing plant breeders. If the breeding goal is wide adaptation, the best strategy would be to identify several different environments within the region and place a test location in each to select for adaptability (Gauch \& Zobel, 1997). The GEI and stability of crop performance across environments are become more relevant issue in the 21 st century as greater emphasis is placed on sustainable agricultural systems. The current study is focused on investigation of genotype by Environment ( $\mathrm{G}$ x E) interaction, yield stability analysis to identify high yielder and most stable genotypes for specific and wider adaptation.

\section{MATERIALS AND METHODS}

2.1 Description of study areas

Table: 1 Description of study areas

\begin{tabular}{lccccccc}
\hline Location & Longitude & Latitude & Altitude in m.a.s.l & Soil type & Rainfall in mm & Minimum T $^{\circ}$ & Maximum $^{\text {o }}$ \\
\hline A/ Minch & $42^{\circ} 15^{\prime} \mathrm{E}$ & $9^{\circ} 10 \mathrm{~N}$ & 1297 & vertisol & 710 & 16.5 & 32.5 \\
Shoarobit & $39^{\circ} 93^{\prime} \mathrm{E}$ & $10^{\circ} 35^{\prime} \mathrm{N}$ & 1500 & vertisol & 890.7 & 14.5 & 29.5 \\
Kobo & $39^{\circ} 38^{\prime} \mathrm{E}$ & $12^{\circ} 09^{\prime} \mathrm{N}$ & 1513 & vertisol & 650 & 17.5 & 31 \\
Sheraro & $38^{\circ} 9^{\prime} \mathrm{E}$ & $14^{\circ} 6^{\prime} \mathrm{N}$ & 1179 & vertisol & 623 & 19 & 36 \\
\hline
\end{tabular}

\subsection{Genetic materials}

A total of 84 hybrid lines were used in this study. The advanced sorghum hybrid lines used in this study was developed by national sorghum research program.

Table: 2 List of genotypes used in the study

\begin{tabular}{lllll}
\hline No. & Genotype & Female & Male & Pedigree \\
1 & TX623A/03MW6049 & TX623A & 03MW6049 & TX623A/03MW6049 \\
2 & ICSA34/05MI5065 & ICSA34 & 05MI5065 & ICSA34/05MI5065 \\
3 & MARC 6A/ICSR 50 & MARC 6A & ICSR 50 & MARC 6A/ICSR 50 \\
4 & TX623A/ETSL 100134 & TX623A & ETSL 100134 & TX623A/ETSL 100134 \\
5 & MARC 6A/ETSL 101565 & MARC 6A & ETSL 101565 & MARC 6A/ETSL 101565 \\
6 & MARC 4A/ETSL 101701 & MARC 4A & ETSL 101701 & MARC 4A/ETSL 101701 \\
7 & PU207A/PRL984357 & PU207A & PRL984357 & PU207A/PRL984357 \\
8 & ICSA 21 A/PRL 984084 & ICSA 21 A & PRL 984084 & ICSA 21 A/PRL 984084 \\
9 & ICSA-21/ETSL 100540 & ICSA-21 & ETSL 100540 & ICSA-21/ETSL 100540 \\
10 & MARC 6A/IESV 23010DL & MARC 6A & IESV 23010DL & MARC 6A/IESV 23010DL \\
11 & MARC 4A/ETSL 100661 & MARC 4A & ETSL 100661 & MARC 4A/ETSL 100661 \\
12 & P850341A/ICSR101 & P850341A & ICSR101 & P850341A/ICSR101 \\
13 & MARC 6A/ICSR 93034 & MARC 6A & ICSR 93034 & MARC 6A/ICSR 93034 \\
14 & MARC 6A/ETSL 100318 & MARC 6A & ETSL 100318 & MARC 6A/ETSL 100318 \\
15 & TX623A/PRL984212 & TX623A & PRL984212 & TX623A/PRL984212 \\
16 & MARC 4A/IESV 92168-DC & MARC 4A & IESV 92168-DC & MARC 4A/IESV 92168-DC \\
17 & PU207A/PRL984212 & PU207A & PRL984212 & PU207A/PRL984212 \\
18 & MARC 6A/ICSV 93041 & MARC 6A & ICSV 93041 & MARC 6A/ICSV 93041 \\
19 & TX623A/PRL984394 & TX623A & PRL984394 & TX623A/PRL984394 \\
20 & ICSA 34/Gambella 1107 & ICSA 34 & Gambella 1107 & ICSA 34/Gambella 1107 \\
21 & TX623A/PRL984096 & TX623A & PRL984096 & TX623A/PRL984096 \\
22 & TX623A/99MW4043 & TX623A & 99MW4043 & TX623A/99MW4043 \\
\hline
\end{tabular}




\begin{tabular}{|c|c|c|c|c|}
\hline No. & Genotype & Female & Male & Pedigree \\
\hline 23 & MARC 4A/ETSL 101565 & MARC 4A & ETSL 101565 & MARC 4A/ETSL 101565 \\
\hline 24 & TX623A/PRL984336 & TX623A & PRL984336 & TX623A/PRL984336 \\
\hline 25 & TX623A/ACC\#69349 & TX623A & ACC\#69349 & TX623A/ACC\#69349 \\
\hline 26 & ICSA10/Gambella1107 & ICSA10 & Gambella1107 & ICSA10/Gambella1 107 \\
\hline 27 & TX623A/ETSL 100684 & TX623A & ETSL 100684 & TX623A/ETSL 100684 \\
\hline 28 & MARC 6A/ACC\#69349 & MARC 6A & ACC\#69349 & MARC 6A/ACC\#69349 \\
\hline 29 & ICSA88006/PRL983935 & ICSA88006 & PRL983935 & ICSA88006/PRL983935 \\
\hline 30 & MARC 4A/ICSR 14 & MARC 4A & ICSR 14 & MARC 4A/ICSR 14 \\
\hline 31 & P9529A/ETSL 101580 & P9529A & ETSL 101580 & P9529A/ETSL 101580 \\
\hline 32 & TX623A/PRL984206 & TX623A & PRL984206 & TX623A/PRL984206 \\
\hline 33 & P9529A/Misikir & P9529A & Misikir & P9529A/Misikir \\
\hline 34 & MARC 4A/ETSL 100318 & MARC 4A & ETSL 100318 & MARC 4A/ETSL 100318 \\
\hline 35 & MARC 6A/ETSL 100666 & MARC 6A & ETSL 100666 & MARC 6A/ETSL 100666 \\
\hline 36 & MARC 6A/PDL984931 & MARC 6A & PDL984931 & MARC 6A/PDL984931 \\
\hline 37 & TX623A/PRL984362 & TX623A & PRL984362 & TX623A/PRL984362 \\
\hline 38 & ESH-4 & PU209A & PU304 & PU209A/PU304 \\
\hline 39 & PU207A/PRL984104 & PU207A & PRL984104 & PU207A/PRL984104 \\
\hline 40 & ICSA 34/PRL 984084 & ICSA 34 & PRL 984084 & ICSA 34/PRL 984084 \\
\hline 41 & ICSA-21/ETSL 100638 & ICSA-21 & ETSL 100638 & ICSA-21/ETSL 100638 \\
\hline 42 & TX623A/ETSL 100123 & TX623A & ETSL 100123 & TX623A/ETSL 100123 \\
\hline 43 & TX623A/IESV 92045DL & TX623A & IESV 92045DL & TX623A/IESV 92045DL \\
\hline 44 & MARC 6A/IESV 92168-DC & MARC 6A & IESV 92168-DC & MARC 6A/IESV 92168-DC \\
\hline 45 & MARC 4A/01MS7013 & MARC 4A & $01 \mathrm{MS} 7013$ & MARC 4A/01MS7013 \\
\hline 46 & MARC 6A/ETSL 101853 & MARC 6A & ETSL 101853 & MARC 6A/ETSL 101853 \\
\hline 47 & MARC 4A/M204 & MARC 4A & M204 & MARC 4A/M204 \\
\hline 48 & TX623A/IESV 23010DL & TX623A & IESV 23010DL & TX623A/IESV 23010DL \\
\hline 49 & TX623A/ETSL 101578 & TX623A & ETSL 101578 & TX623A/ETSL 101578 \\
\hline 50 & MARC 4A/05MW6028 & MARC 4A & 05MW6028 & MARC 4A/05MW6028 \\
\hline 51 & ICSA34/Gambella1107 & ICSA34 & Gambella1107 & ICSA34/Gambella1107 \\
\hline 52 & ICSA88006/M204 & ICSA88006 & M204 & ICSA88006/M204 \\
\hline 53 & TX623A/PRL984192 & TX623A & PRL984192 & TX623A/PRL984192 \\
\hline 54 & ICSA-21/ETSL 101578 & ICSA-21 & ETSL 101578 & ICSA-21/ETSL 101578 \\
\hline 55 & MARC 6A/ETSL 101845 & MARC 6A & ETSL 101845 & MARC 6A/ETSL 101845 \\
\hline 56 & ICSA 34/Misikir & ICSA 34 & Misikir & ICSA 34/Misikir \\
\hline 57 & ICSA15/M5568 & ICSA15 & M5568 & ICSA15/M5568 \\
\hline 58 & MARC5A/2005MI5093 & MARC5A & 2005MI5093 & MARC5A/2005MI5093 \\
\hline 59 & ICSA-21/ETSL 100649 & ICSA-21 & ETSL 100649 & ICSA-21/ETSL 100649 \\
\hline 60 & ICSA22//ICSR24010/B35 & ICSA22 & ICSR24010/B35 & ICSA22//ICSR24010/B35 \\
\hline 61 & TX623A/ICSR 93034 & TX623A & ICSR 93034 & TX623A/ICSR 93034 \\
\hline 62 & MARC 6A/01MS7013 & MARC 6A & $01 \mathrm{MS} 7013$ & MARC 6A/01MS7013 \\
\hline 63 & PU207A/PRL984245 & PU207A & PRL984245 & PU207A/PRL984245 \\
\hline 64 & PU207A/PRL984109 & PU207A & PRL984109 & PU207A/PRL984109 \\
\hline 65 & PU207A/PRL984088 & PU207A & PRL984088 & PU207A/PRL984088 \\
\hline 66 & P9529A/ETSL 101564 & P9529A & ETSL 101564 & P9529A/ETSL 101564 \\
\hline 67 & MARC 6A/99MI5081 & MARC 6A & 99MI5081 & MARC 6A/99MI5081 \\
\hline 68 & CK60A/PRL984042 & CK60A & PRL984042 & CK60A/PRL984042 \\
\hline 69 & MARC 4A/IESV 92084-DL & MARC 4A & IESV 92084-DL & MARC 4A/IESV 92084-DL \\
\hline 70 & TX623A/01MS7013 & TX623A & $01 \mathrm{MS} 7013$ & TX623A/01MS7013 \\
\hline 71 & MARC 6A/ICSR 14 & MARC 6A & ICSR 14 & MARC 6A/ICSR 14 \\
\hline 72 & TX623A/PRL984182 & TX623A & PRL984182 & TX623A/PRL984182 \\
\hline 73 & ICSA 10/Misikir & ICSA 10 & Misikir & ICSA 10/Misikir \\
\hline 74 & MARC 4A/ICSR 93034 & MARC 4A & ICSR 93034 & MARC 4A/ICSR 93034 \\
\hline 75 & MARC 6A/03MW6049 & MARC 6A & 03MW6049 & MARC 6A/03MW6049 \\
\hline 76 & MARC 6A/PGRC/E\#222880 & MARC 6A & PGRC/E\#222880 & MARC 6A/PGRC/E\#222880 \\
\hline 77 & TX623A/PGRC/E\#222880 & TX623A & PGRC/E\#222880 & TX623A/PGRC/E\#222880 \\
\hline 78 & TX623A/PRL984165 & TX623A & PRL984165 & TX623A/PRL984165 \\
\hline 79 & ICSA88006/WSV387 & ICSA88006 & WSV387 & ICSA88006/WSV387 \\
\hline 80 & ICSA 10/Gambella 1107 & ICSA 10 & Gambella 1107 & ICSA 10/Gambella 1107 \\
\hline
\end{tabular}




\begin{tabular}{lllll}
\hline No. & Genotype & Female & Male & Pedigree \\
81 & ICSA21/MR747 & ICSA21 & MR747 & ICSA21/MR747 \\
82 & MARC5A/IESV92207DL & MARC5A & IESV92207DL & MARC5A/IESV92207DL \\
83 & P9529A/ETSL 100282 & P9529A & ETSL 100282 & P9529A/ETSL 100282 \\
84 & MARC 6A/ETSL 101565 & MARC 6A & ETSL 101565 & MARC 6A/ETSL 101565 \\
\hline
\end{tabular}

2.3 Statistical analysis

Data collected on 84 sorghum genotypes developed by the Ethiopian institute of agricultural research, National sorghum research program variety were subjected to analysis of variance (ANOVA) for key grain yield in order to check the presence of significant difference among genotypes. The analysis of variance of the combined data expresses the observed (Yij) mean yield of the $i$ th genotype at the $j$ th environment as: $\boldsymbol{Y} \boldsymbol{i j}=\boldsymbol{\mu}+\boldsymbol{G i}+\boldsymbol{E} \boldsymbol{j}+\boldsymbol{G E} \boldsymbol{i j}+$ eij (Fisher, 1925; Martin, 2004). Where $\mu$ is the general mean; Gi, Ej, and GEij represent the effect of the genotype, environment, and the GEI, respectively; and eij is the average of the random errors associated with the $r$ th plot that receives the $i$ th genotype in the $j$ th environment.

\section{RESULTS AND DISCUSSION}

\subsection{Analysis of variance across test environment}

Combined analysis of variance (ANOVA) across locations for grain yield) revealed highly significant variability among the genotypes with significant environment, and genotype by environment interaction effect (Table 3 ). Similar findings have been reported by Fentie M, Assefa A, Belete K (2013).

3.2 AMMI Analysis of Variance for G X E Interaction

The AMMI analysis is presented in Table 3. The MMI analysis of variance for grain yield ( $\left.\mathrm{kg} \mathrm{ha-}{ }^{1}\right)$ of 84 sorghum genotypes evaluated across four environments revealed that the main effects of genotypes $(G)$ and environments (E) accounted for $16.0 \%$ and $62.5 \%$ of the treatment sum of squares, respectively. The $\mathrm{G} \times \mathrm{E}$ interaction also accounted for $21.5 \%$ of the treatment sum square. The analysis showed that variations due to genotype (G), environment $(\mathrm{E})$ and genotype by environment $(\mathrm{G} \times \mathrm{E})$ were significant $(\mathrm{P}<0.001)$. The large sum of squares (Table 3 ) for environment indicated that the environment were diverse, with large differences among environments causing most of the variation in grain yield, which is in similar with the Patnaik MC, (2009) Fentie M, Assefa A, Belete K (2013) and (MoA), (2010) findings, in which the environments exhibited larger sum of squares than that of the genotypes. The presence of G x E interaction (GEI) was obviously confirmed by the AMMI model, when the interaction was partitioned, among the first two interaction principal component axis (IPCA) (Table 3). The first (IPCA1) is highly significant $(\mathrm{P}<0.001)$ by capturing $57.8 \%$ of the total variation in the GxE interaction sum square, while the second interaction PCA is not significant.

Table: 3 Analysis of AMMI Model

\begin{tabular}{lllllrl}
\hline Source & Df & Ss & Ms & Vr & F pr & \% Explained Ss \\
Treatments & 335 & 2723349773 & $8129402^{* *}$ & 5.73 & $<0.001$ & \\
Block & 4 & 3677025 & $919256^{\text {ns }}$ & 0.65 & 0.629 & \\
Genotypes & 83 & 436331787 & $5257009^{* *}$ & 3.70 & $<0.001$ & 16.0 \\
Environments & 3 & 1701706474 & $567235491^{* *}$ & 617.06 & $<0.001$ & 62.5 \\
GxE & 249 & 585311512 & $2350649^{* *}$ & 1.66 & $<0.001$ & 21.5 \\
IPCA 1 & 85 & 338839372 & $3986346^{* *}$ & 2.81 & $<0.001$ & 57.8 \\
IPCA 2 & 83 & 160040495 & $1928199^{\text {ns }}$ & 1.36 & 0.032 & \\
Total & 671 & 3198182651 & 4766293 & & & \\
Error & 332 & 471155853 & 1419144 & & & \\
\hline
\end{tabular}

3.3 AMMI Stability Analysis and Grain Yield Performance

The ranking of 84 sorghum genotypes based on their mean yield and stability performance are shown in Figure 1. The line transient through the bi-plot origin is called the average tester coordinate (ATC), which is defined by the average PC1 and PC2 scores of all environments (Yan W, and MS Kang 2003). The line which passes through the origin and is perpendicular to the ATC represents the stability of genotypes. Either direction away from the bi-plot origin on this axis indicates greater GE interaction and reduced stability. For selection, the ideal genotypes are those with both high mean yield and high stability. In the bi-plot, they are close to the origin and have the shortest vector from the ATC.

As displayed in Figure 2, the genotype G2, followed by G16, can be considered as genotypes with both high yield and stability performance. The genotypes with highest yielding performance but relatively with low stability were G74 and 15, whereas the genotypes with low yield and low stability were G51, G78, and G25. The other genotypes on the right side of the line with no arrow have yield performance greater than mean yield and the genotypes on the left side of this line had yields less than mean yield. Among the genotypes, G2 was the most 
stable, followed by G6 with better mean yield performance. According to this bi-plot (Figure 2), G74 can be recommended for specific adaptation whereas G2 and G16 relatively for wider adaptation which is similar with (Taddesse Lakew, 2017).

The environment vector of GGE biplot and gives the summary of the interrelationship among test environments in the study (Figure 1). The biplot describes the first two principal components and accounted for $76.3 \%$ of the total variation in grain yield. The lines that connect the test environment to the biplot origin are called environment vectors. The angles between the vectors of the two environments approximate the correlation coefficient between them (Kroonenberg, 1995; Yan 2002). So, the angle between KB and AM, SH and SR and $\mathrm{KB}$ and SR were all less than $90^{\circ}$. Thus the four environments are said to be positively correlated to one another. Comparison biplot (Total - 76.30\%)

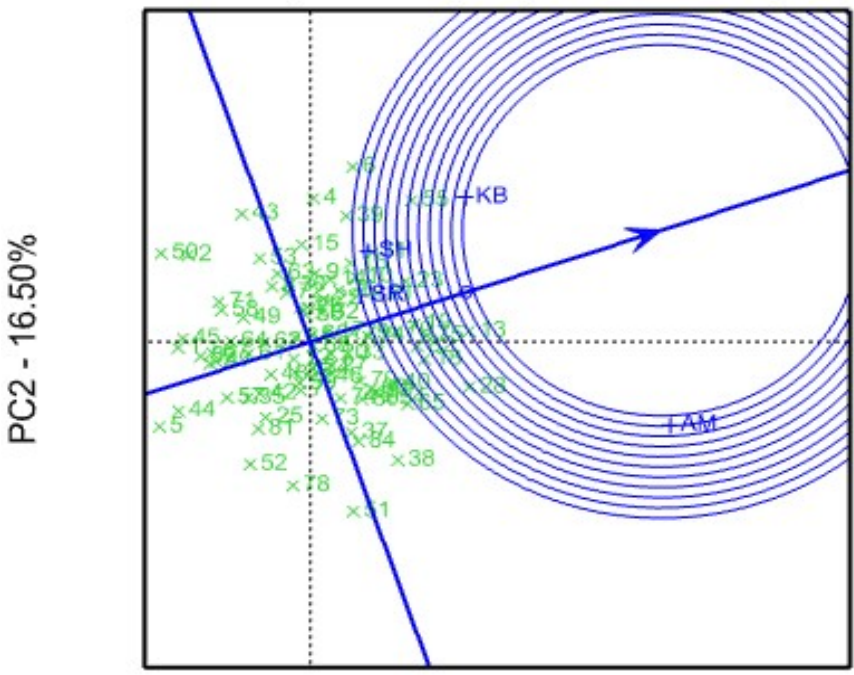

PC1 - 59.80\%

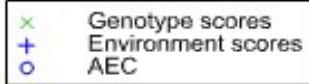

Figure: 1 Comparison biplot

Ranking biplot (Total - 58.57\%)

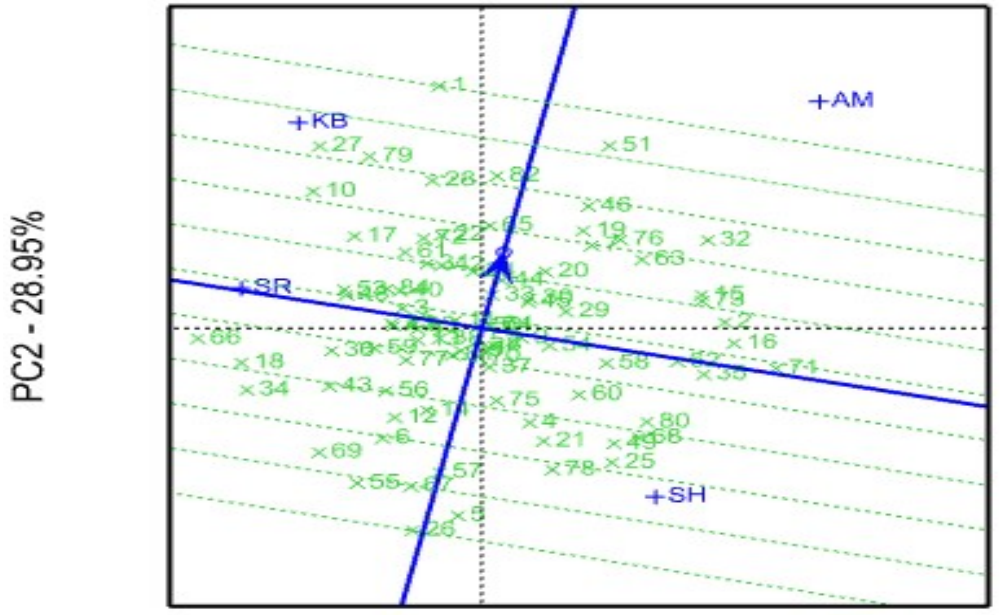

PC1 - 29.62\%

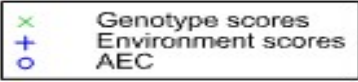

Figure: 2 ranking biplot and yield stability 


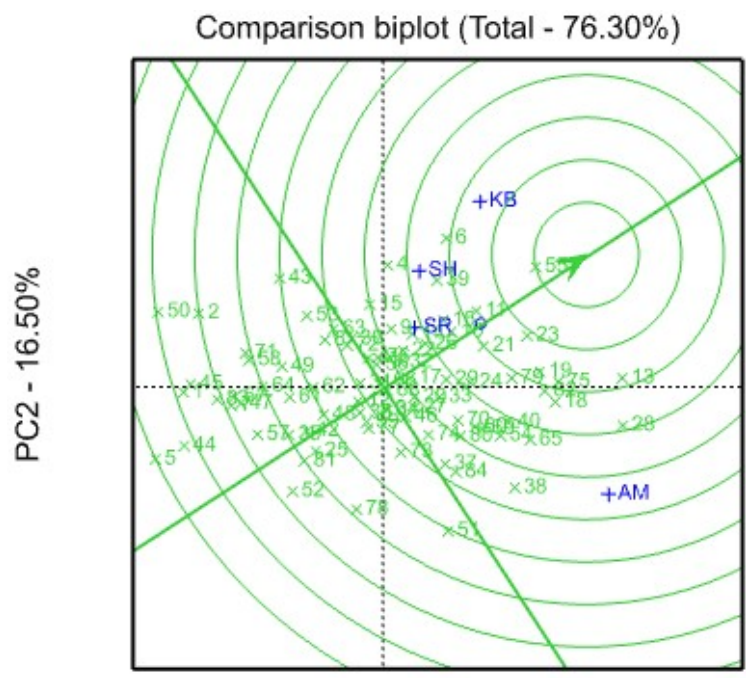

PC1 $-59.80 \%$

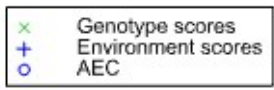

Figure: 3 Ranking genotypes by mean grain yield and stability across environments

3.4 Stability Analysis Based on AMMI and GGE Models

The environmental scores are joined to the origin by side lines (Figure 5). Sites with short spokes do not exert strong interactive forces while, those with long spokes exert strong interaction (Tadesse, 2017). Hence, environments $\mathrm{AM}$ and $\mathrm{SH}$ exerted strong interaction forces while the rest two did less. On the other hand, the genotypes near the origin are not sensitive to environmental interaction and those distant from the origins are sensitive and have large interaction. In the present study, G1, G5, G66, G71, G18, G10 and G25 had more responsive since they were far away from the origin whereas, the genotypes G54, G29, G23, G4, G9, G5, G43, G13 and G7 were close to the origin and hence they were less sensitive to environmental interactive forces while genotypes G38, G11, G45 and G76 were the most closest to the origin and hence had almost no interaction forces (Figure 2).

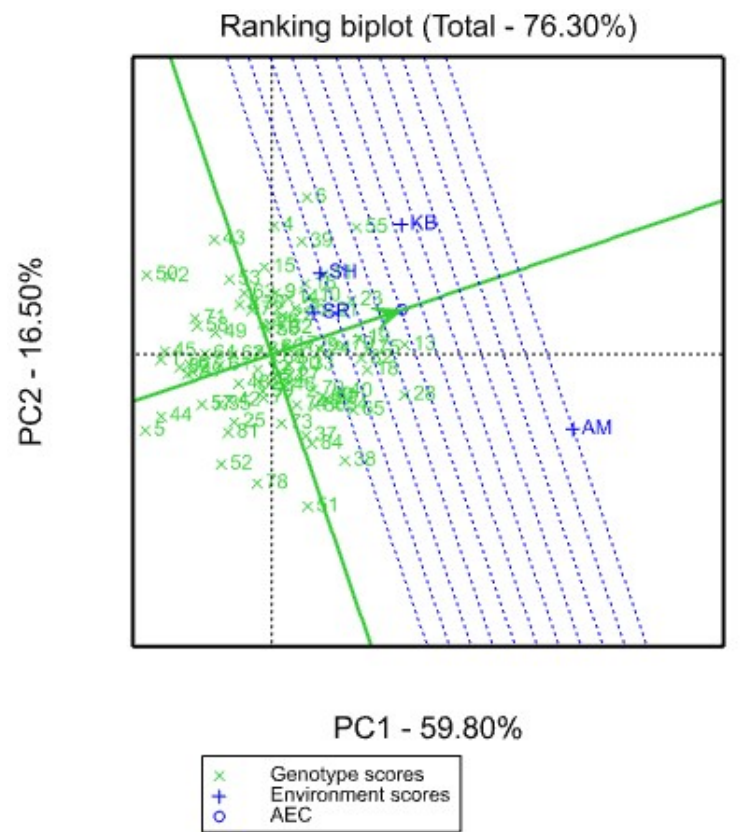

Figure: 4 ranking GGE biplot of genotypes 


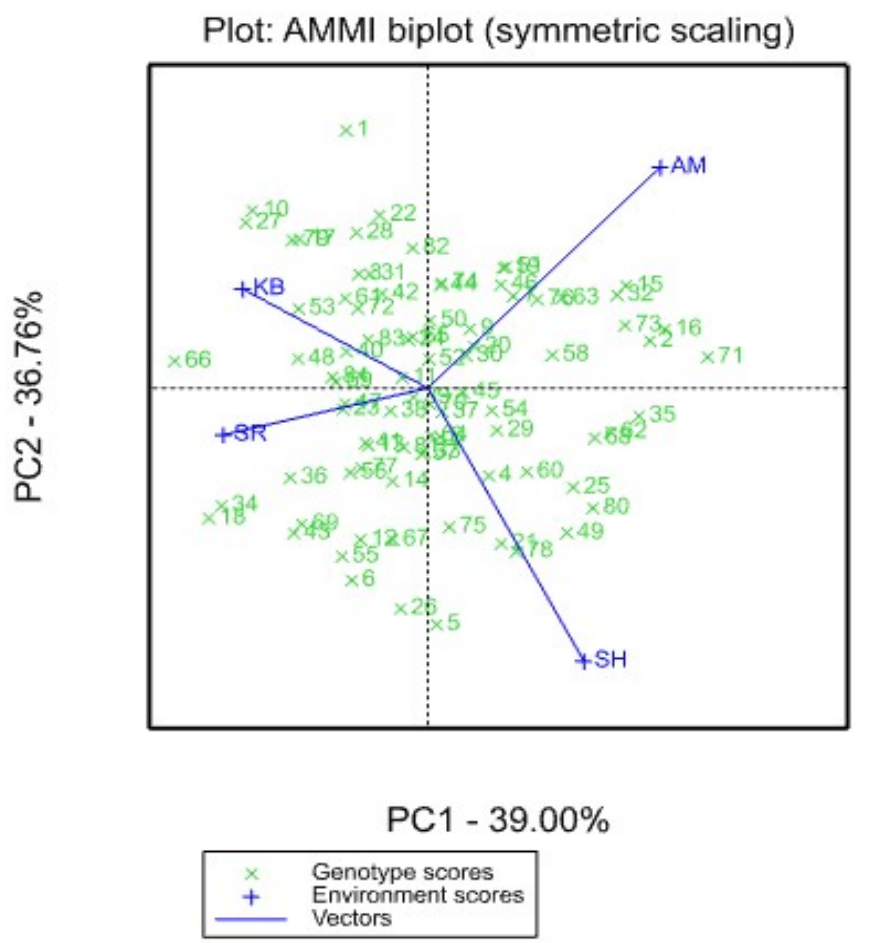

Figure: 5 AMMI-1 Biplot

In AMMI-2 biplot (Figure 6), if a genotype or an environment has an IPCA1 score of nearly zero, it has small interaction effects and considered as stable. When a genotype and environment have the same sign on the PCA axis, their interaction is positive and if different, their interaction is negative Zobel RW, (1988). Genotypes and environments on the same parallel lines have similar yields and a genotype or environment on the right side of the midpoint of this axis has higher yields than those of left hand side. Accordingly, among sorghum genotypes, G13, G18, G28, 74, 55 and G82 generally exhibited high yield of positive IPCA1 score, out of which G28 and G13 had high IPCA1 scores in which G28 being the overall best genotype. Hence, the G28 was identified as specially adapted and the highest yielding genotype to the corresponding environments (Figure 6). On the other hand G22, G4, 43 and G53 were high yielding genotypes with negative IPCA1 scores. Out of 84 lines, G52, G22, G8 and G55 were with near zero IPCA scores and hence have less interaction with the environments out of which only G55 and G22 had above average yield performance. Among environments, KB exhibited near zero IPCA1 score and hence had small interaction effects indicating that all the genotypes performed well in this location. So, it is the most favorable environments for most genotypes while AM, SR and SH were good for only few genotypes Adugna A (2007) and Anandan A, (2009) reported similar pattern of interactions. 


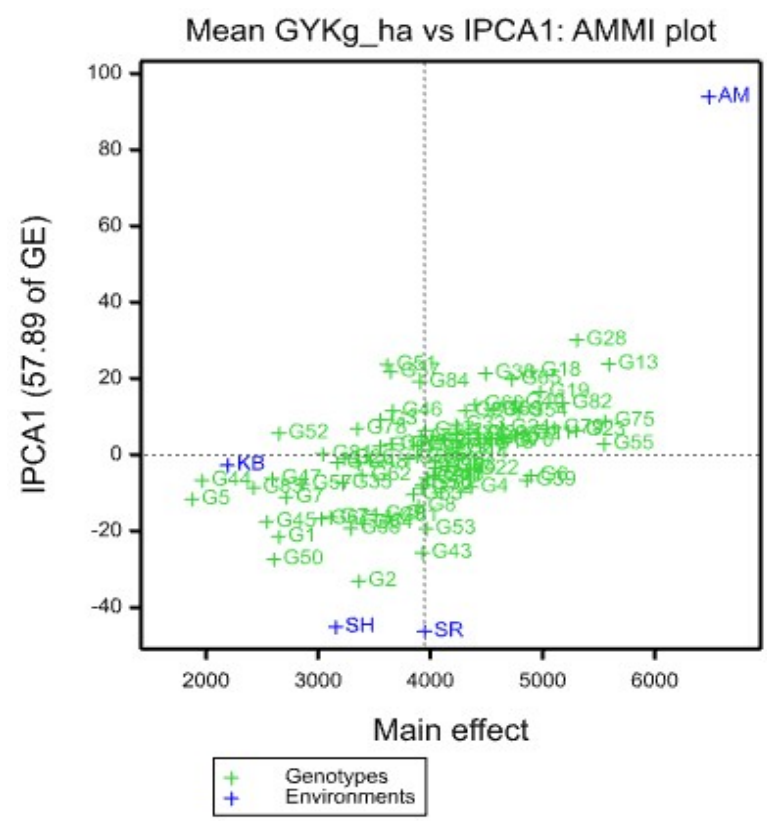

Figure: 6 AMMI-2 Biplot

\subsection{GGE bi-plot Analysis}

GGE bi-plot can best recognize GxE interaction pattern of data and visibly shows which genotypes perform best in which environments. GGE and AMMI models are equivalent as far as their accuracy is concerned (Sheng et al, 2000). The polygon view of the GGE bi-plot (Figure 7) indicates the best genotype(s) in each environment (Hunt LA, 2002). The vertex genotypes (G71, G32, G51, G27, G1, G66 and G26) have the longest vectors, in their respective direction, which is a measure of responsiveness to environments. The vertex genotypes for each sector are the ones that gave the highest yield for the environments that fall within that sector (Tadesse, 2017). The genotype with the high yield in SR is G66, and in KB G27, G10, G79 in SH G25, G78, G86, G68. In SR the best genotypes is G66. The other vertex genotypes (G1, G32, G51, 71 and G26, are poorest in all environments because there is no location in their sectors.

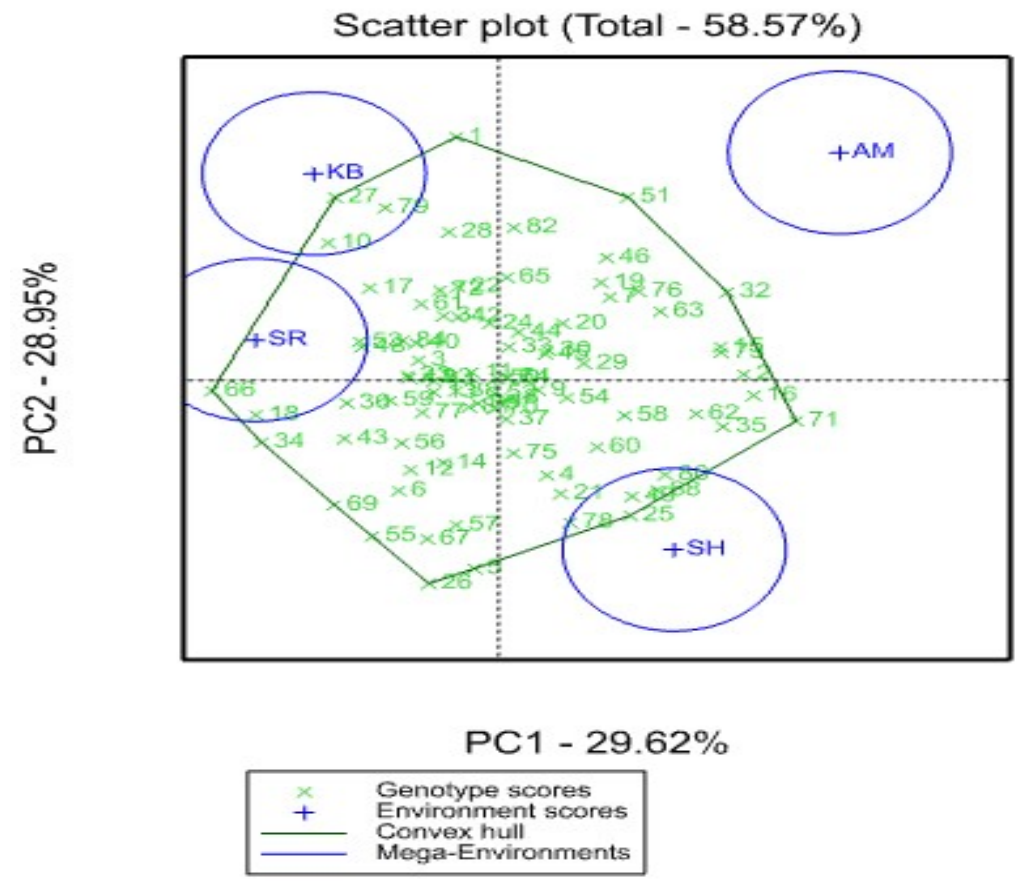

Figure: 7 Polygon views of GGE-biplot showing sorghum genotypes with respect to Mega environments 


\section{SUMMRY AND CONCLUSION}

GxE interactions and effects of genetic background GxE interactions are complex phenomena which complicate the interpretation of genetical experiments and often make predictions difficult and it is an important issue facing plant breeders as the breeding goal is wide adaptation, the best strategy would be to identify several different environments within the region and place a test location in each to select for adaptability. Developing best performing and stable sorghum genotypes across different environments is of ultimate importance to plant breeders. This study was conducted using 84 hybrid lines across different locations to identify the most stable and high yielding genotypes.

The results specified that yield performance of sorghum genotypes were influenced by genotype (G), the environments (E) and genotype by environmental interaction effects. The MMI analysis of variance for grain yield (kg ha- ${ }^{1}$ ) of 84 sorghum genotypes evaluated across four environments revealed that the main effects of genotypes (G) and environments (E) accounted for $16.0 \%$ and $62.5 \%$ of the treatment sum of squares, respectively. The $G \mathrm{x}$ E interaction also accounted for $21.5 \%$ of the treatment sum square. It also showed that variations due to genotype $(G)$, environment $(E)$ and genotype by environment $(G \times E)$ were significant $(P<0.001)$. The large sum of squares for environment indicated that the environment were diverse, with large differences among environments causing most of the variation in grain yield. Among the first two interaction principal component axis (IPCA), the first (IPCA1) is highly significant $(\mathrm{P}<0.001)$ by capturing $57.8 \%$ of the total variation in the GxE interaction sum square, while the second interaction PCA is not significant.

GGE bi-plot obviously shows which genotypes perform best in which environments. The vertex genotypes (G71, G32, G51, G27, G1, G66 and G26) have the longest vectors, in their respective direction, which is a measure of responsiveness to environments. The vertex genotypes for each sector are the ones that gave the highest yield for the environments that fall within that sector. The high yielder genotype in SR is G66, and in KB G27, G10, G79 in SH G25, G78, G86, G68. In SR the best genotypes is G66. The other vertex genotypes (G1, G32, G51, 71 and $\mathrm{G} 26$, are poorest in all environments.

Among the first two principal components, IPCA1 accounted for $57.8 \%$ of the total variation in grain yield. The angles among the vectors of the two environments estimated the correlation coefficient between them. The angle between $\mathrm{KB}$ and $\mathrm{AM}, \mathrm{SH}$ and SR and $\mathrm{KB}$ and SR were all less than $90^{\circ}$. Hence, the four environments are said to be positively correlated to one another.

The sites with short spokes do not exert strong interactive forces while, those with long spokes exert strong interaction. Hence, environments AM and SH exerted strong interaction forces while the rest two did less. On the other hand, the genotypes near the origin are not sensitive to environmental interaction and those distant from the origins are sensitive and have large interaction. Accordingly, G1, G5, G66, G71, G18, G10 and G25 had more responsive since they were far away from the origin whereas G54, G29, G23, G4, G9, G5, G43, G13 and G7 were close to the origin and hence they were less sensitive to environmental interactive forces while, G38, G11, G45 and G76 were the most closest to the origin and hence had almost no interaction forces. In general, this result suggests, G74 for specific adaptation whereas G2 and G16 relatively for wider adaptation.

\section{REFERANCES}

Adugna A (2007). Assessment of Yield Stability in Sorghum. African Crop Science Journal. 15: 83-92.

Anglani, C. 1998. Sorghum for human food: a review. Plant Foods and Human Nutrition, 52: 85-89.

Anandan A, Eswaran R, Sabesan T, Prakash M (2009) Additive main effects and multiplicative interactions analysis of yield performances in rice genotypes under coastal saline environments. Advances in Biological Research 3: 43-48.

Bibi A, Sadaqat, H.A. Akram, H.M. and Mohammed, M.I. 2010. Physiological markers for screening sorghum (Sorghum bicolor) germplasm under water stress condition. International Journal of Agricultural Biology, 12: $451-455$.

Boyer, J.S. (1982) Plant Productivity and Environment. Science, 218, 443-448. https://doi.org/10.1126/science.218.4571.443.

Centeral Statistics Agency for Ethiopia, 2018. Report on area and production of major crops. Addis Ababa, Ethiopia.

Fisher, R.A. 1925. Statistical methods for research workers. Oliver and Boyd, London.

Yan W (2002) Singular value partitioning in biplot analysis of multienvironment trial data. Agron J 94: 990-996.

Doggett, H. 1988. Sorghum 2nd Edition Tropical Agriculture, Series Longman Scientific \& Technical, Essex, England.

Paterson, A.H., Bowers, J.E., Bruggmann, R., Dubchak, I., Grimwood, J., Gundlach, H., Haberer, G., Hellsten, U., Mitros, T., Poliakov, A. and Schmutz, J., 2009. The Sorghum bicolor genome and the diversification of grasses. Nature, 457(7229), pp.551-556.

Yan W, Kang MS (2003) GGE Biplot Analysis: A Graphical Tool for Breeders, Geneticists and Agronomists. 1st Edn., CRC Press LLC., Boca Roton, Florida, pp: 271. 
Yan W, Hunt LA (2002). Biplot analysis of diallel data. Crop Sci 42:21-30.

Yan, W., L.A. Hunt, Q. Sheng and Z. Szlavnics. (2000). Cultivar evaluation and mega-environment investigation based on the GGE biplot. Crop Sci. 40: 597-605.

Fentie M, Assefa A, Belete K (2013). Ammi Analysis of Yield Performance and Stability of Finger Millet Genotypes Across Different Environments. World Journal of Agricultural Sciences 9: 231-237.

McGuire, S.J. 2007. Vulnerability in farmer seed Systems: Farmer practices for coping with seed insecurity for sorghum in Eastern Ethiopia. Economic Botany,61 (3).

MESFIN ABATE, 2016 Assessment of Striga infestation and Evaluation of sorghum landraces for Resistance/Tolerance to [Striga hermonthica (Del.) Benth] in North-Western Ethiopia. Haramaya University, Dire Dawa, Ethiopia.

Ministry of Agriculture and Rural Development (MoA), (2010). National Rice Research and Development Strategy of Ethiopia. Addis Ababa, Ethiopia, pp. 48.

USDA, 2017. World Agricultural Production U.S. Department of Agriculture Foreign Agricultural Service / Office of Global Analysis, International Production Assessment Division (IPAD). Washington, DC 20250-1051 http://www.pecad.fas.usda.gov/

Zobel RW, Wright MJ, Gauch HG (1988). Statistical analysis of a yield trial. Agronomy Journal.80: 388-393. 